\title{
PENYULUHAN TENTANG BAHAYA PERGAULAN BEBAS DAN BIJAK BERMEDIA SOSIAL
}

\author{
Agus Rofi'i*, Rama Dwika Herdiawan, Eka Nurhidayat, Afief Fakhrudin, \\ Dadang Sudirno, Dede Salim Nahdi \\ Universitas Majalengka \\ *agusrafii@unma.ac.id
}

\begin{abstract}
One of the current social problems is the problem of promiscuity and wise social media that occurs among teenagers. There are two impacts of promiscuity and intelligent behavior in using social media among teenagers, namely juvenile delinquency and the use of social media. As we know that there are many harmful effects of juvenile delinquency and tend to be negative, such as, promiscuity that causes free sex can be fatal to health. Free sex can occur because of the influence of the environment and a person's choice of the environment where he hangs out. In addition, use of social media what we must do is how to use social media wisely. The purpose of community service activities is to increase knowledge by providing counseling about the dangers of promiscuity and social media wisdom among adolescents. It is hoped that there will be changes in learning and behavior towards the dangers of promiscuity and social media knowledge among adolescents. This activity was carried out twice, namely first by providing counseling about the risks of promiscuity among teenagers, secondly, by using social media wisely in daily life so that negative things are fortified. The results of this service indicate that there is an increase in knowledge and a positive response.
\end{abstract}

Keywords; promiscuity; social media-wise; teenagers

\begin{abstract}
Abstrak
Salah satu masalah sosial saat ini adalah masalah pergaulan bebas dan bijak bermedsos yang terjadi pada kalangan remaja. Ada dua dampak yang ditimbulkan dari perilaku pergaulan bebas dan bijak bermedos di kalangan remaja yaitu kenakalan remaja dan penggunaan media sosial. Seperti kita ketahui bahwa banyak dampak buruk dari kenakalan remaja dan cenderung bersifat negatif seperti halnya, pergaulan bebas yang menimbulkan seks bebas dapat berakibat fatal bagi kesehatan. Seks bebas dapat terjadi karena pengaruh dari lingkungan dan salah pilihnya seseorang terhadap lingkungan tempatnya bergaul. Selain itu juga penggunaan media sosial yang harus kita lakukan adalah bagaiamana cara menggunakan media sosaial secara bijak. Tujuan kegiatan pengabdian masyarakat adalah meningkatkan pengetahuan dengan memberikan penyuluhan tentang bahaya pergaulan bebas dan bijak media sosial di kalangan remaja, dan diharapkan terjadinya perubahan pengetahuan dan perilaku terhadap bahaya pergaulan bebas dan bijak media sosial di kalangan remaja. Kegiatan ini dilaksanakan dua kali yaitu pertama dengan memberikan penyuluhan tentang bahaya pergaulan bebas di kalangan remaja, kedua dengan cara bijak menggunakan media sosial dalam kehiduan sehari-hari, agar terbentengi hal-hal yang negatif. Hasil dari pengabdian ini menunjukkan bahwa ada peningkatan pengetahuan dan respon yang positif bagi para remaja.
\end{abstract}

Kata Kunci: pergaulan bebas; bijak media sosial; remaja

Submitted: 2021-08-24

Revised: 2021-10-21

Accepted: $2021-10-28$

\section{Pendahuluan}

Di zaman sekarang ini media sosial hal yang sangat umum, setiap orang pasti memiliki akun media sosial. Salah satu fungsinya sebagai media bersosialisasi di dunia maya dan bisa menjangkau aktifitas seseorang di media sosial. Melalui media sosial orang bisa mencari sesuatu yang di cari, seperti mencari informasi yang berdampak kepada hal yang negatif. Dengan hal itu kita harus memahami etika bermedia sosial sehingga jangan sampai terjerumus kearah yang negatif. Penyalahgunaan pergaulanlah yang mengawali adanya pergaulan bebas di kalangan remaja, saat ini media yang sering digunakan untuk mendapatkan semua hal tentang pergaulan bebas adalah internet. Pergaulan melalui media juga harus pintar memilih teman sejawat yang membawa kearah posistif, jangan sampai membawa dampak negatif. Kehidupan yang kita alami, salah satu tahap yang paling ingat adalah masa remaja, karena dimasa remaja banyak dipenuhi 
dengan pengalaman-pengalaman yang tak terlupakan selain masa remaja. Salah satu bentuk perilaku menyimpang adalah melewati batas norma yang ada.

Pergaulan bebas ini sering kita dengar baik masyarakat sekitar maupun dari media masa atau media sosial. Menurut Sulaeman (1995:2) mengatakan bahwa masa remaja merupakan suatu masa, dimana individu berjuang untuk tumbuh dan menjadi sesuatu, menggali serta memahami arti dan makna dari segala sesuatu yang ada. Selain itu, masa remaja adalah peralihan dari masa anak ke masa dewasa yang mengalami perkembangan semua aspek atau fungsi untuk memasuki masa dewasa (Saputro, 2018:25-32).

Menurut Sendari (2021), Pergaulan bebas penting dipahami, terutama untuk generasi muda. Pergaulan bebas bisa memberi dampak buruk bagi pertumbuhan anak dan remaja. Tak hanya untuk anak, pergaulan bebas juga bisa merugikan orang-orang di sekitarnya, dan sering dikaitkan dengan kenakalan remaja. Perilaku pergaulan bebas sering tidak terkontrol dan bisa menjerumuskan anak ke berbagai hal negatif. Pengertian pergaulan bebas berhubungan dengan faktor lingkungan sekitar. Remaja merupakan generasi penerus yang akan membangun bangsa yang lebih baik dan mempunyai pemikiran jauh ke depan dan dapat menguntungkan diri sendiri, keluarga, dan lingkungan sekitar. Maka dari itu remaja tersebut harus mendapatkan perhatian yang lebih, baik oleh dirinya sendiri, keluarga, dan lingkungan sekitar. Banyak kita lihat di media masa maupun kita lihat di media elektronik adanya remaja yang berprestasi juga ada remaja yang melakukan perbuatan yang merugikan dirinya sendiri, keluarga dan lingkungan sekitar.

Menurut Destiawati dkk, (2020:404-409) Teknologi komunikasi telah berkembang demikian pesatnya. Penyediaan akses informasi yang tak kenal batas dan waktu seperti layanan internet menjadi alat komunikasi yang penting saat ini, sehingga kita seolaholah dimanjakan oleh perkembangan teknologi sistem informasi tersebut. Dengan media sosial itu berfungsi untuk memudahkan kita menjalin interaksi dengan banyak orang. Sekaligus sebagai tempat untuk kita berbagi pikiran, dan informasi. Tapi, dengan segala kemudahan yang tersedia, tentu kita harus waspada dan perlu bijak dalam bermedia sosial agar tetap aman dan tidak menimbulkan dampak yang negatif. Jangan sampai hal yang harusnya menguntungkan semua pihak malah berbalik menjadi menimbulkan masalah yang tidak pernah kamu harapkan sebelumnya, makanya perlu dijaga oleh kita bersama karena dengan pergaulan bebas dan tidak paham tentang bagaiaman cara bijak bermedia sosial. Adanya masalah ataupun tidak tergantung bagaimana setiap orang menggunakannya. Oleh sebab itu, tidak ada salahnya mulai belajar bagaimana cara menggunakan media sosial secara bijak agar terhindar dari hal-hal yang merugikan dirinya sendiri, keluarga, dan lingkungan sekitar.

Selain itu juga agar bisa menggunakan media sosial dengan tenang dan aman, Banyaknya persoalan tentang media yang berkembang dimasa ini termasuk hoax yang bisa menyasar berbagai kalangan termasuk kalangan anak remaja ini, minim nya pengetahuan sehingga terjadi banyak kasus, dan berujung di penjara, dengan diadakan sosialisasi ini masalah yang akan dihadapi bisa terpecahkan oleh kalangan remaja dan karang taruna untuk menjadikan desanya sebagai desa cakap digital, peka digitalisasi terdapat beberapa cara menggunakan media sosial dengan bijak yang akan dijelaskan dalam penyuluhan ini.

Dalam rangka penyuluhan pergaulan bebas dan bagaimana cara bijak bermedia sosial, pengusul mengajukan pengabdian masyarakat di wilayah Majalengka pada anak remaja sebagai sasaran penyuluhan atau sosialisasi bahaya pergaulan dan bijak bermedia sosial. Adapun penyuluhannya bertema tentang: "Penyuluhan Bahaya Pergaulan Bebas dan Bijak bermedia Sosial".

Dari data analisis diatas, permasalahan yang akan dicarikan solusinya dalam rangka mencegah bahasa pergaulan bebas dan bijak bermedia sosial adalah:

1. Dengan cara melakukan penyuluhan ini diupayakan memberi pengetahuan tentang bahaya pergaulan bebas dan etika bijak menggunakan media sosial 
2. Sejauh mana kesadaran para anak remaja tentang menyikapi pergaulan bebas dan bijak bermedia sosial.

3. Bagaimana upaya pencegahan dan penaggulanya terhadap bahaya pergaulan bebas dan etika bijak bermedia sosial.

Kegiatan ini bertujuan yang ingin dicapai dari kegiatan penyuluhan pergaulan bebas dan bijak bermedia sosial:

1. Memberikan pengetahuan tentang materi bagaimana bahaya pergaulan bebas

2. Memberikan gambaran tentang menggunakan media sosial secara bijak.

3. Memberikan gambaran dari dampak positif dan negatif dari bahaya pergaulan bebas dan penggunaan media sosial secara bebas di kalangan remaja.

4. Membantu untuk mendorong para remaja untuk memiliki karakter yang baik.

\section{Metode}

Pelaksanaan pengabdian masyarakat dilakukan dengan melakukan sosialisasi atau penyuluhan pada peserta anak remaja serta pembentukan teman sejawat remaja melakukan penyuluhan, dan teknik pelaksanaan program dengan menggunakan sampling ke seluruh para remaja. Maka penyuluhan dilaksanakan dengan metode sebagai berikut : a) ceramah (Luring/Tatap muka), b) Diksusi, c) Tanya Jawab, dan d) Metode interaktif (adisti dkk, 2021:54).

\section{Hasil dan Pembahasan}

1. Waktu Pelaksanaan

Kegiatan pengabdian masyarakat berupa "Penyuluhan Pergaulan Bebas dan Bijak Bermedia Sosial, dilaksanakan pada bulan September dibalai desa Panjalin Kidul Sumberjaya Majalengka. Sasaran pengabdian ini adalah aparatur desa, para remaja masyarakat desa panjalin kidul sumberjaya. Program pengabdian ini hari rabu tanggal 15 bulan September 2021. Materi penyuluhan yang dipaparkan dalam kegiatan ini dapat dilihat pada tabel 1 .

Tabel 1. Penyuluhan Pergaulan Bebas dan Bijak Bermedia Sosial

\begin{tabular}{|c|c|c|c|c|c|}
\hline No & Program kerja & $\begin{array}{l}\text { Waktu/ } \\
\text { Tempat }\end{array}$ & Peserta & Tujuan & Narasumber \\
\hline 1 & $\begin{array}{l}\text { Penyuluhan } \\
\text { Bahaya } \\
\text { Pergaulan } \\
\text { Bebas dan Bijak } \\
\text { Bermedia Sosial }\end{array}$ & $\begin{array}{l}\text { Rabu, } \\
15 / 09 / 2021 \\
19.30- \\
21.00 \text { WIB } \\
\text { Luring: } \\
\text { Balai Desa } \\
\text { Panjalin } \\
\text { kidul }\end{array}$ & $\begin{array}{l}20 \text { org : } \\
\text { Aparatur } \\
\text { Desa, } \\
\text { masyarakat }\end{array}$ & $\begin{array}{l}\text { Di tekankan kepada para } \\
\text { pelajar agar menghindari } \\
\text { Pergaulan Bebas dan Bijak } \\
\text { Bermedia Sosial, membantu } \\
\text { memberikan gambaran } \\
\text { kepada kaum remaja untuk } \\
\text { dapat membentengi diri dari } \\
\text { kemudahaan mendapatkan } \\
\text { informasi negative dari } \\
\text { media sosial }\end{array}$ & $\begin{array}{l}\text { Dr. H. Agus } \\
\text { Rofi'i,.M.Pd } \\
\text { (UNMA) }\end{array}$ \\
\hline
\end{tabular}

Sementara kegiatan agenda penyuluhan dan sosialisasinya dilaksanakan dalam satu hari, untuk lebih jelas, lihat rinciannya seperti tabel 2. 
Tabel 2. Agenda Kegiatan Penyuluhan Pergaulan Bebas dan Bijak Bermedia Sosial

\begin{tabular}{|c|c|c|c|c|}
\hline Waktu & Kegiatan & Peserta & Narasumber & Pemandu \\
\hline 19.30 & Registrasi & $\begin{array}{l}20 \text { org : } \\
\text { Aparatur }\end{array}$ & & $\begin{array}{l}\text { Panitia TIM } \\
\text { Penyuluh }\end{array}$ \\
\hline 20.00 & $\begin{array}{l}\text { Pembukaan } \\
\text { Sambutan }\end{array}$ & $\begin{array}{l}\text { Desa, } \\
\text { masyarakat }\end{array}$ & & $\begin{array}{l}\text { "Pergaulan Bebas } \\
\text { dan Bijak Bermedia }\end{array}$ \\
\hline 20.30 & Pemateri & & Dr. H. Agus Rofi'i, M.Pd & Sosial" \\
\hline 21.30 & $\begin{array}{l}\text { Sesi Tanya } \\
\text { Jawab }\end{array}$ & & Panitia Penyuluh/Pembicara & \\
\hline 22.00 & Penutup & & Tim Penyuluhan & \\
\hline
\end{tabular}

2. Kegiatan yang dilaksanakan

Kegiatan ini dilaksanakan selama 2 hari di Desa Panjalin kidul kecamatan sumberjaya kabupaten majalengka dengan melibatkan peserta Kuliah Kerja Mahasiswa Gerakan Nasional Revolusi Mental untuk membantu pelaksanaan persiapan penyuluhan dan pelaksanaan kegiatan. Ada beberapa tahapan yang dilakukan dalam persiapan kegiatan yaitu :

a. Membagikan quesionare tentang pergaulan bebas dan bijak bermedia sosial kepada remaja, setelah itu teknik pelaksanaan programnya menggunakan sampling.

b. Mempersipakan materi dan bahan penyuluhan pergaulan bebas dan bijak bermedia sosial.

c. Selanjutnya melakukan penyuluhan pergaulan bebas dan bijak bermedia sosial.

Tabel 3. Pelaksanaan Program Pergaulan Bebas dan Bijak Bermedia Sosial

\begin{tabular}{lllll}
\hline $\begin{array}{c}\text { Nama } \\
\text { Program } \\
\text { Kerja }\end{array}$ & $\begin{array}{c}\text { Teknik } \\
\text { Pelaksanaan } \\
\text { Program }\end{array}$ & $\begin{array}{c}\text { Dampak Yang di Rasakan } \\
\text { terhadap Kegiatan } \\
\text { Program } \\
\text { (Masyarakat/Kelompok } \\
\text { Masyarakat) }\end{array}$ & $\begin{array}{c}\text { Output/Hasil Pelaksanaan } \\
\text { Program }\end{array}$ & Keterangan \\
\hline $\begin{array}{l}\text { Penyuluhan } \\
\text { bahaya }\end{array}$ & Sampling & $\begin{array}{l}\text { Remaja/pelajar/karang } \\
\text { taruna/aparatur desa }\end{array}$ & $\begin{array}{l}\text { Remaja/pelajar/karang } \\
\text { taruna mampu memiliki }\end{array}$ & kami \\
pergaulan & memahami dan bijak & wawasan dalam menyikapi & jadikan \\
bebas dan & dalam pola perkembangan & secara bijak media sosial & sampel \\
bijak & anak muda di zaman & baik itu berita hoax, dan & dalam \\
bermedia & sekarang dengan pola & berita berita yang ilegal & pelaksanan \\
sosial & pendekatan yang intens & dalam secara keseluruhan, & program ini \\
& dan pola pengawasan & serta dalam pergaulan bebas & \\
& yang terpantua untuk & yang membuka wawasan & \\
& perkembangannya. & semua harus masuk pada & \\
& & generasi sekarang. & \\
\hline
\end{tabular}

Kegiatan telah dilakukan tentang bahaya pergaulan bebas dan bijak bermedia sosial bagi anak remaja dengan jumlah 30 peserta. Kegiatan ini memberikan informasi mengenai bahaya dan dampak dari kenakalan remaja, dan etika dengan menggunakan media sosial di kalangan remaja. Selama kegiatan tersebut di dampingi oleh para tokoh masyarakat dan yang peduli tentang bahaya pergaulan bebas.

Sebagian besar peserta mengatakan sudah memahami apa yang dimaksud bahaya pergaulan bebas, penyebabnya, dampaknya, bagaimana cara pencegahannya, dan etika bermedia sosial. Namun, sebagian masih kurang memahami pada beberapa bagian materi karena masih belum memperhatikan dan belum mempunyai rasa ingin tahu tentang materi pergaulan bebas dan bijak bermedia sosial. Sebagian besar peserta memperhatikan dengan seksama pada materi penyuluhan 
BERNAS:

yang diberikan, walaupun sebagian lainnya masih belum memperhatikan. Pengetahuan peserta mengenai pergauolan bebas dan bijak bermedia sosial pada kalangan remaja meningkat. Selanjutnya, Monitoring dilakukan dengan observasi langsung pada saat kegiatan penyuluhan dengan melihat interaksi antara peserta dengan pemateri saat penyuluhan. Evaluasi yang dilakukan dengan metode diskusi, tanya jawab, dan metode interaktif terkait materi tersebut.

Hasil data survei dilapangan tentang penyuluhan pergaulan bebas dan bijak bermedia sosial dapat dilihat pada tabel 4.

Tabel 4. Data Survei Pergaulan Bebas dan Bijak Bermedsos

\begin{tabular}{|c|c|c|c|c|c|c|c|}
\hline No & Nama & $\begin{array}{c}\text { Media Sosial } \\
\text { yang } \\
\text { digunakan }\end{array}$ & $\begin{array}{c}\text { Perangkat yang } \\
\text { digunakan }\end{array}$ & $\begin{array}{c}\text { Alasan } \\
\text { Mengakses } \\
\text { Media Sosial }\end{array}$ & $\begin{array}{c}\text { Alokasi } \\
\text { Waktu } \\
\text { menggunaka } \\
\text { n medsos }\end{array}$ & $\begin{array}{c}\text { Apakah } \\
\text { Orangtua } \\
\text { selalu } \\
\text { mengarahkan } \\
\text { anda untuk } \\
\text { memilih } \\
\text { pergaulan } \\
\text { yang benar? }\end{array}$ & $\begin{array}{c}\text { Apakah } \\
\text { lingkungan } \\
\text { berpengaruh } \\
\text { pada } \\
\text { pergaulan } \\
\text { anda? }\end{array}$ \\
\hline 1 & Apip & $\begin{array}{c}\text { Facebook } \\
\text { Instagram } \\
\text { Whatsapp } \\
\text { Twitter }\end{array}$ & $\begin{array}{l}\text { Smartphone } \\
\text { Laptop }\end{array}$ & $\begin{array}{c}\text { Bisnis } \\
\text { Pendidikan } \\
\text { Komunikasi } \\
\text { Hiburan }\end{array}$ & $8 \mathrm{JAM}$ & $\mathrm{Ya}$ & $\mathrm{Ya}$ \\
\hline 2. & Amel & $\begin{array}{l}\text { Instagram } \\
\text { Whatsapp }\end{array}$ & Smartphone & $\begin{array}{l}\text { Komunikasi } \\
\text { Pendidikan }\end{array}$ & $<1$ JAM & Ya & Ya \\
\hline 3. & Azizah & Whatsapp & Smartphone & Komunikasi & $<1$ JAM & Ya & Tidak \\
\hline 4. & Dea & Instagram & Smartphone & Hiburan & $1 \mathrm{JAM}$ & Ya & Tidak \\
\hline 5. & Eka & Instagram & Smartphone & Komunikasi & 8 JAM & Tidak & Ya \\
\hline 6. & Dimas & Whatsapp & Smartphone & Pendidikan & $<1 \mathrm{JAM}$ & $\mathrm{Ya}$ & Ya \\
\hline 7. & Irfandi & Whatsapp & Smartphone & Pendidikan & $<1$ JAM & Ya & Ya \\
\hline 8. & Aswan & $\begin{array}{l}\text { Whatsapp } \\
\text { Facebook }\end{array}$ & Smartphone & $\begin{array}{l}\text { Hiburan } \\
\text { Komunikasi }\end{array}$ & 1 JAM & Ya & Ya \\
\hline 9. & Davit & Whatsapp & Smartphone & $\begin{array}{l}\text { Pendidikan } \\
\text { Komunikasi }\end{array}$ & $<1$ JAM & Tidak & Tidak \\
\hline 10. & Gibran & Whatsapp & Tablet & Hiburan & $<1$ JAM & Ya & Tidak \\
\hline 11. & Indah & $\begin{array}{l}\text { Whatsapp } \\
\text { Instagram } \\
\text { Tiktok }\end{array}$ & Smartphone & $\begin{array}{l}\text { Hiburan } \\
\text { Pendidikan } \\
\text { Komunikasi }\end{array}$ & $8 \mathrm{JAM}$ & Ya & Ya \\
\hline 12. & Anggun & $\begin{array}{l}\text { Whatsapp } \\
\text { Iinstagram }\end{array}$ & Smartphone & $\begin{array}{l}\text { Pendidikan } \\
\text { Hiburan } \\
\text { Komunikasi }\end{array}$ & 1 JAM & Ya & Ya \\
\hline 13. & Dewi & $\begin{array}{l}\text { Whatsapp } \\
\text { Facebook }\end{array}$ & Smartphone & $\begin{array}{l}\text { Pendidikan } \\
\text { Hiburan } \\
\text { Komunikasi }\end{array}$ & 1 JAM & Ya & Ya \\
\hline 14. & Dian & $\begin{array}{l}\text { Whatsapp } \\
\text { Instagram } \\
\text { Twitter }\end{array}$ & Smartphone & $\begin{array}{l}\text { Pendidikan } \\
\text { Hiburan } \\
\text { Komunikasi }\end{array}$ & $1 \mathrm{JAM}$ & Ya & Ya \\
\hline 15. & Bagus & Whatsapp & Smartphone & $\begin{array}{l}\text { Pendidikan } \\
\text { Komunikasi }\end{array}$ & $<1$ JAM & Ya & Ya \\
\hline 16. & Bagas & Instagram & Smartphone & Pendidikan & $1 \mathrm{JAM}$ & Ya & Tidak \\
\hline 17. & Hafidz & Whatsapp & Smartphone & Komunikasi & $<1$ JAM & Ya & Ya \\
\hline 18. & Albi & $\begin{array}{l}\text { Whatsapp } \\
\text { Instagram } \\
\text { Facebook }\end{array}$ & Smartphone & $\begin{array}{l}\text { Komunikasi } \\
\text { Pendidikan } \\
\text { Hiburan }\end{array}$ & $1 \mathrm{JAM}$ & Ya & Ya \\
\hline 19. & Dimas & $\begin{array}{l}\text { Facebook } \\
\text { Instagram } \\
\text { Whatsapp }\end{array}$ & Smartphone & $\begin{array}{l}\text { Hiburan } \\
\text { Komunikasi }\end{array}$ & $1 \mathrm{JAM}$ & Ya & Ya \\
\hline 20. & Ananda & $\begin{array}{l}\text { Facebook } \\
\text { Instagram } \\
\text { Whatsapp }\end{array}$ & Smartphone & Komunikasi & 8 JAM & Ya & Ya \\
\hline 21. & Aldy & Instagram & Smartphone & Hiburan & $1 \mathrm{JAM}$ & Ya & Ya \\
\hline 22. & Kania & $\begin{array}{l}\text { Facebook } \\
\text { Instagram }\end{array}$ & Smartphone & $\begin{array}{l}\text { Pendidikan } \\
\text { Hiburan }\end{array}$ & 1 JAM & Ya & Ya \\
\hline
\end{tabular}




\begin{tabular}{|c|c|c|c|c|c|c|c|}
\hline & & Whatsapp & & Komunikasi & & & \\
\hline 23. & Cindy & $\begin{array}{l}\text { Instagram } \\
\text { Whatsapp } \\
\text { Tiktok }\end{array}$ & Smartphone & $\begin{array}{l}\text { Bisnis } \\
\text { Pendidikan } \\
\text { Hiburan } \\
\text { Komunikasi }\end{array}$ & $8 \mathrm{JAM}$ & Ya & $\mathrm{Ya}$ \\
\hline 24. & Anisa & $\begin{array}{l}\text { Facebook } \\
\text { Instagram } \\
\text { Whatsapp }\end{array}$ & Smartphone & $\begin{array}{l}\text { Pendidikan } \\
\text { Hiburan }\end{array}$ & $8 \mathrm{JAM}$ & $\mathrm{Ya}$ & Ya \\
\hline 25. & Charitz & $\begin{array}{l}\text { Facebook } \\
\text { Instagram } \\
\text { Whatsapp }\end{array}$ & $\begin{array}{l}\text { Smartphone } \\
\text { Laptop }\end{array}$ & $\begin{array}{l}\text { Pendidikan } \\
\text { Hiburan } \\
\text { Komunikasi }\end{array}$ & $8 \mathrm{JAM}$ & Ya & Ya \\
\hline 26. & Aas & $\begin{array}{l}\text { Instagram } \\
\text { Whatsapp }\end{array}$ & Smartphone & $\begin{array}{l}\text { Pendidikan } \\
\text { Hiiburan } \\
\text { Komunikasi }\end{array}$ & $8 \mathrm{JAM}$ & Ya & Ya \\
\hline 27. & Elsa & $\begin{array}{l}\text { Whatsapp } \\
\text { Instagram } \\
\text { Tiktok }\end{array}$ & Smartphone & $\begin{array}{l}\text { Hiburan } \\
\text { Pendidikan } \\
\text { Komunikasi }\end{array}$ & $8 \mathrm{JAM}$ & Ya & Ya \\
\hline 28. & Alif & $\begin{array}{c}\text { Facebook } \\
\text { Instagram } \\
\text { Whatsapp } \\
\text { Twiter }\end{array}$ & Smartphone & $\begin{array}{l}\text { Bisnis } \\
\text { Pendidikan } \\
\text { Hiburan } \\
\text { Komiunikasi }\end{array}$ & $8 \mathrm{JAM}$ & Ya & $\mathrm{Ya}$ \\
\hline 29. & Mila & $\begin{array}{l}\text { Instagram } \\
\text { Whatsapp }\end{array}$ & Smartphone & $\begin{array}{l}\text { Hiburan } \\
\text { komunikasi }\end{array}$ & $1 \mathrm{JAM}$ & Ya & Ya \\
\hline 30. & Nabila & $\begin{array}{l}\text { Facebook } \\
\text { Instagram } \\
\text { Whatsapp }\end{array}$ & Smartphone & $\begin{array}{l}\text { Pendidikan } \\
\text { Hiburan } \\
\text { Komunikasi }\end{array}$ & $8 \mathrm{JAM}$ & Tidak & Tidak \\
\hline
\end{tabular}

Tabel 4. menunjukan survei peserta tentang pergaulan bebas dan bijak bermedia sosial, bisa kita lihat pada gambar 1.

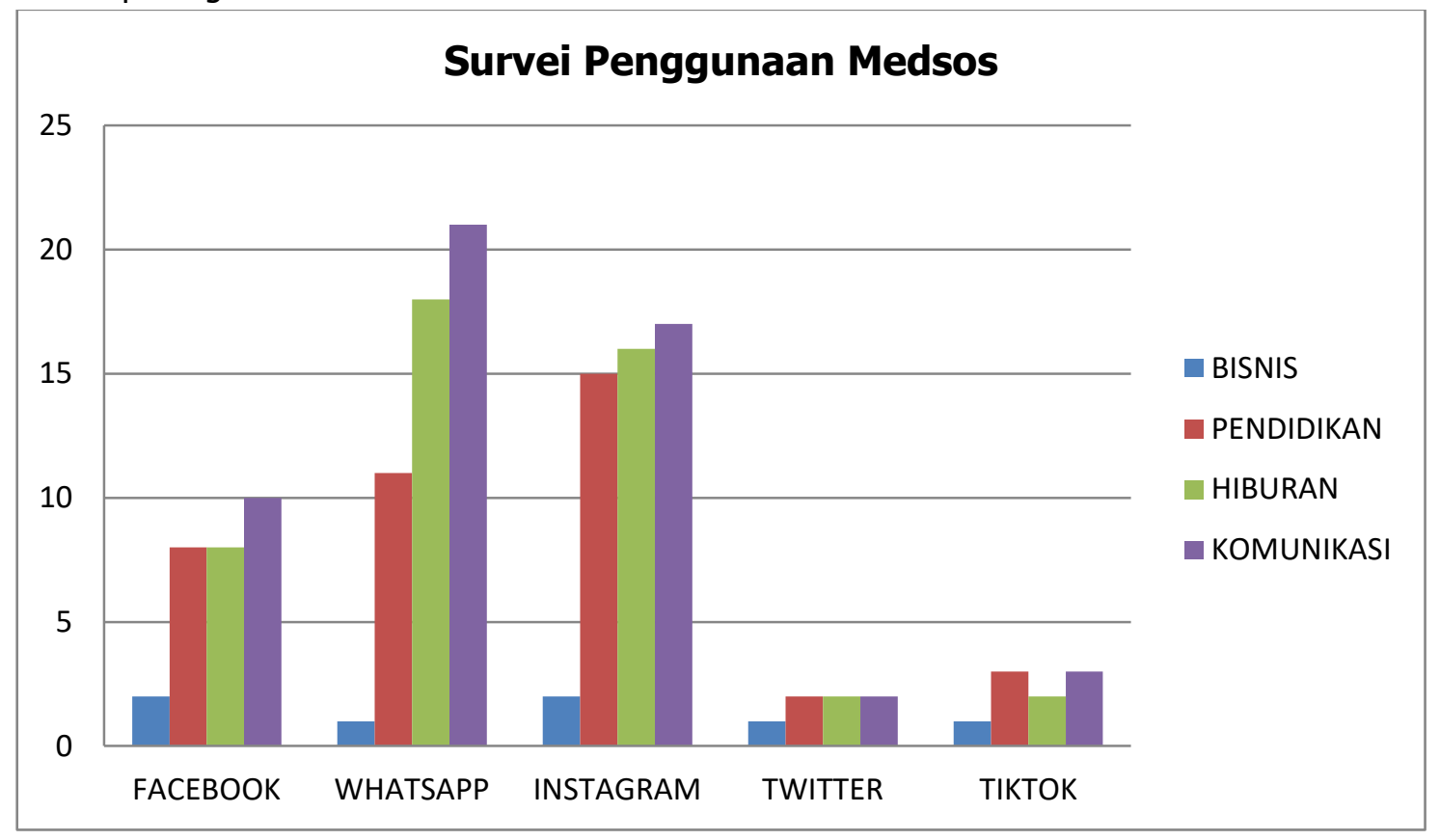

Gambar 2. Survei Penggunaan Media Sosial

Hasil survei penggunaan media sosial kita lihat dari diagram, peserta lebih banyak menggunakan media sosial untuk berkomunikasi dibandingkan dengan menggunakan facebook, whatsapp, instagram, twitter, dan tiktok. 

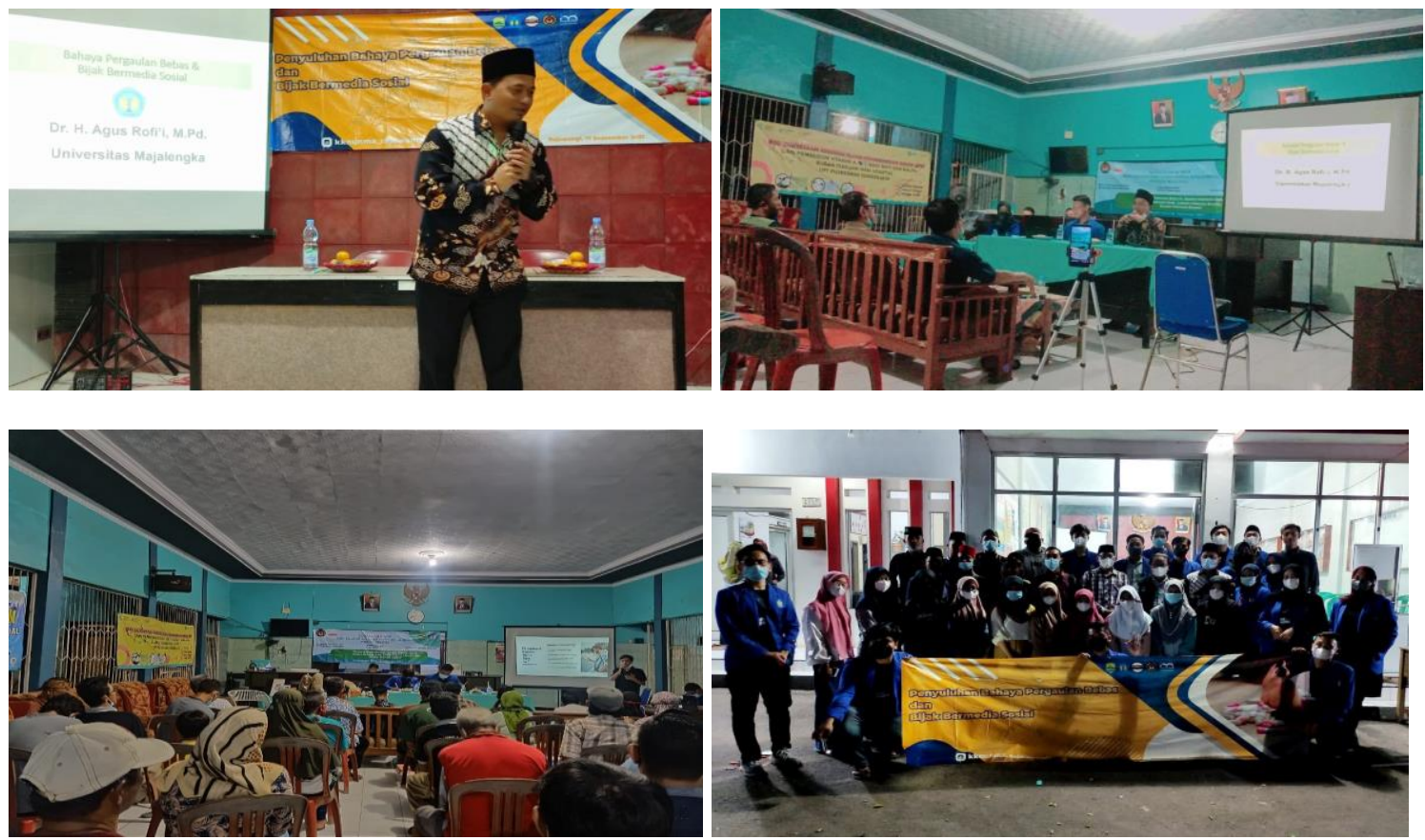

Gambar 2. Kegiatan Penyuluhan Pergaulan Bebas dan Bijak Bermedia Sosial

\section{Kesimpulan}

Kegiatan pengabdian ini merupakan pelaksanaan programpengabdian masyarakat (PKM), fakta di lapangan bahwa penyuluhan yang dilaksanakan di Desa Panjalin Kidul Majalengka pada hari Rabu tanggal 15 September 2021 dengan tema "Penyuluhan Bahaya Pergaulan Bebas dan Bijak Bermedia Sosial", yang diharapkan dalam kegiatan pengabdian ini adalah 1). Perubahan perilaku dalam pergaulan bebas bagi para remaja, 2). Kepedulian para remaja tentang hal dalam pergaulan bebas, 3). Para remaja paham tentang cara bagaimana bijak melalui media sosial, dan 4) Bagi orang tua diharapkan agar lebih meningkatkan pengawasan kepada puta putrinya agar lebih waspada dan hati-hati dalam mengambil setiap tindakan.

Saran dalam kegiatan ini adalah kegiatan ini sangat penting bagi orang tua dan masyarakat sekitar dalam membantu para peserta untuk meningkatkan pengetahuan dalam pergaulan bebas dan bijak media sosial.

\section{Daftar Pustaka}

Adisti, N. A., Nashriana, N., \& Rumesten, I. (2021). Penyuluhan Tentang Pencegahan Contempt Of Court Di Lembaga Pembinaan Khusus Anak Palembang. BERNAS: Jurnal Pengabdian Kepada Masyarakat, 2(1), 52-59. https://doi.org/10.31949/jb.v2i1.606

Destiawati, F., Paramita, A., Dhika, H., \& Jaya, M. (2020). Sosialisasi Etika Pemanfaatan Teknologi Media Sosial Dalam Penyampaian Informasi Sesuai UU ITE. BERNAS: Jurnal Pengabdian Kepada Masyarakat, 1(4), 404-409. https://doi.org/10.31949/jb.v1i4.462

Dimas. 2019. 6 Tips Bijak Menggunakan Media Sosial Untuk Para Millenial. Available at: https://bijak-menggunakan-media-sosial/

S, Dwi. 2019. Cara Bijak Menggunakan Media Sosial. Available at: https://www.brilio.net/creator/8tips-menggunakan-media-sosial-dengan-bijak-dan-tetap-amanad078c.html

Setyaningsih, R. (2014). Bahaya Berkomunikasi di media sosial. Jurnal Psikologi Proyeksi, Vol. 9 (2), $91-103$ 
Saputro, K. Z. (2018). Memahami ciri dan tugas perkembangan masa remaja. Aplikasia: Jurnal Aplikasi IImu-IImu Agama, 17(1), 25-32.

Sulaeman, Dadang. (1995). Psikologi Remaja. Bandung: Mandar Maju.

Sendari, (2021) pergaulan bebas penyebab dampak dan cara mencegahnya, https://hot.liputan6.com/read/4663920/

Pristiwanti, D. O. (2013). Pergaulan Bebas Pada Remaja di Era Globalisasi. Jurnal IImiah, 